\title{
Nonlinear coupled fixed point theorems in ordered generalized metric spaces with integral type
}

\author{
Yeol Je Cho ${ }^{1}$, Billy E Rhoades ${ }^{2}$, Reza Saadati ${ }^{3^{*}}$, Bessem Samet ${ }^{4}$ and Wasfi Shatanawi ${ }^{5}$
}

\footnotetext{
* Correspondence: rsaadati@eml.cc ${ }^{3}$ Department of Mathematics, Science and Research Branch, Islamic Azad University, Tehran, Iran Full list of author information is available at the end of the article
}

\begin{abstract}
In this article, we study coupled coincidence and coupled common fixed point theorems in ordered generalized metric spaces for nonlinear contraction condition related to a pair of altering distance functions. Our results generalize and modify several comparable results in the literature. 2000 MSC: 54H25; 47H10; 54E50.

Keywords: ordered set, coupled coincidence point, coupled common fixed point, generalized metric space, altering distance function, weakly contractive condition, contraction of integral type
\end{abstract}

\section{Introduction}

Fixed points of mappings in ordered metric space are of great use in many mathematical problems in applied and pure mathematics. The first result in this direction was obtained by Ran and Reurings [1], in this study the authors presented some applications of their obtained results to matrix equations. In [2,3], Nieto and López extended the result of Ran and Reurings [1] for non-decreasing mappings and applied their result to get a unique solution for a first order differential equation. While Agarwal et al. [4] and O'Regan and Petrutel [5] studied some results for a generalized contractions in ordered metric spaces. Bhaskar and Lakshmikantham [6] introduced the notion of a coupled fixed point of a mapping $F$ from $X \times X$ into $X$. They established some coupled fixed point results and applied their results to the study of existence and uniqueness of solution for a periodic boundary value problem. Lakshmikantham and Ćirić [7] introduced the concept of coupled coincidence point and proved coupled coincidence and coupled common fixed point results for mappings $F$ from $X \times X$ into $X$ and $g$ from $X$ into $X$ satisfying nonlinear contraction in ordered metric space. For the detailed survey on coupled fixed point results in ordered metric spaces, topological spaces, and fuzzy normed spaces, we refer the reader to [6-24].

On the other hand, in [25], Mustafa and Sims introduced a new structure of generalized metric spaces called G-metric spaces. In [26-32], some fixed point theorems for mappings satisfying different contractive conditions in such spaces were obtained. Abbas et al. [33] proved some coupled common fixed point results in two generalized metric spaces. While Shatanawi [34] established some coupled fixed point results in G-

(C) 2012 Cho et al; licensee Springer. This is an Open Access article distributed under the terms of the Creative Commons Attribution License (http://creativecommons.org/licenses/by/2.0), which permits unrestricted use, distribution, and reproduction in any medium, provided the original work is properly cited. 
metric spaces. Saadati et al. [35] established some fixed point in generalized ordered metric space. Recently, Choudhury and Maity [36] initiated the study of coupled fixed point in generalized ordered metric spaces.

In this article, we derive coupled coincidence and coupled common fixed point theorems in generalized ordered metric spaces for nonlinear contraction condition related to a pair of altering distance functions.

\section{Basic concepts}

Khan et al. [37] introduced the concept of altering distance function.

Definition 2.1. A function $\varphi:[0,+\infty) \rightarrow[0,+\infty)$ is called an altering distance function if the following properties are satisfied:

(1) $\varphi$ is continuous and non-decreasing,

(2) $\varphi(t)=0$ if and only if $t=0$.

For more details on the following definitions and results, we refer the reader to Mustafa and Sims [25].

Definition 2.2. Let $X$ be a non-empty set and let $G: X \times X \times X \rightarrow \mathbb{R}^{+}$be a function satisfying the following properties:

(G1) $G(x, y, z)=0$ if and only if $x=y=z$,

(G2) $0<G(x, x, y)$ for all $x, y \in X$ with $x \neq y$,

(G3) $G(x, x, y) \leq G(x, y, z)$ for all $x, y, z \in X$ with $z \neq y$,

(G4) $G(x, y, z)=G(x, z, y)=G(y, z, x)=$...(: symmetry in all three variables),

(G5) $G(x, y, z) \leq G(x, a, a)+G(a, y, z)$ for all $x, y, z, a \in X$.

Then the function $G$ is called a generalized metric or, more specifically, a G-metric on $X$ and the pair $(X, G)$ is called a $G$-metric space.

Definition 2.3. Let $(X, G)$ be a $G$-metric space and $\left(x_{n}\right)$ be a sequence in $X$. We say that $\left(x_{n}\right)$ is G-convergent to a point $x \in X$ or $\left(x_{n}\right) G$-converges to $x$ if, for any $\varepsilon>0$, there exists $k \in \mathbb{N}$ such that $G\left(x, x_{n}, x_{m}\right)<\varepsilon$ for all $m, n \geq k$, that is, $\lim _{n, m \rightarrow+\infty} G\left(x, x_{n}, x_{m}\right)=0$. In this case, we write $x_{n} \rightarrow x$ or $\lim _{n \rightarrow+\infty} x_{n}=x$.

Proposition 2.1. Let $(X, G)$ be a G-metric space. Then the following are equivalent:

(1) $\left(x_{n}\right)$ is G-convergent to $x$.

(2) $G\left(x_{n}, x_{n}, x\right) \rightarrow 0$ as $n \rightarrow+\infty$.

(3) $G\left(x_{n}, x, x\right) \rightarrow 0$ as $n \rightarrow+\infty$.

(4) $G\left(x_{n}, x_{m}, x\right) \rightarrow 0$ as $n, m \rightarrow+\infty$.

Definition 2.4. Let $(X, G)$ be a $G$-metric space and $\left(x_{n}\right)$ be a sequence in $X$. We say that $\left(x_{n}\right)$ is a $G$-Cauchy sequence if, for any $\varepsilon>0$, there exists $k \in \mathbb{N}$ such that $G\left(x_{n}\right.$, $\left.x_{m}, x_{l}\right)<\varepsilon$ for all $n, m, l \geq k$, that is, $G\left(x_{n}, x_{m}, x_{l}\right) \rightarrow 0$ as $n, m, l \rightarrow+\infty$.

Proposition 2.2. Let $(X, G)$ be a G-metric space. Then the following are equivalent:

(1) The sequence $\left(x_{n}\right)$ is a G-Cauchy sequence.

(2) For any $\varepsilon>0$, there exists $k \in \mathbb{N}$ such that $G\left(x_{n}, x_{m}, x_{m}\right)<\varepsilon$ for all $n, m \geq k$. 
Definition 2.5. Let $(X, G)$ and $\left(X^{\prime}, G^{\prime}\right)$ be two $G$-metric spaces. We say that a function $f:(X, G) \rightarrow\left(X^{\prime}, G^{\prime}\right)$ is $G$-continuous at a point $a \in X$ if and only if, for any $\varepsilon>0$, there exists $\delta>0$ such that

$$
x, y \in X, \quad G(a, x, y)<\delta \Rightarrow G^{\prime}(f(a), f(x), f(y))<\varepsilon .
$$

A function $f$ is G-continuous on $X$ if and only if it is $G$-continuous at every point $a \in$ $X$.

Proposition 2.3. Let $(X, G)$ be a G-metric space. Then the function $G$ is jointly continuous in all three of its variables.

We give some examples of $G$-metric spaces.

Example 2.1. Let $(\mathbb{R}, d)$ be the usual metric space. Define a function $G_{s}: \mathbb{R} \times \mathbb{R} \times \mathbb{R}$ $\rightarrow \mathbb{R}$ by

$$
G_{s}(x, y, z)=\mathrm{d}(x, y)+\mathrm{d}(y, z)+\mathrm{d}(x, z)
$$

for all $x, y, z \in \mathbb{R}$. Then it is clear that $\left(\mathbb{R}, G_{s}\right)$ is a $G$-metric space.

Example 2.2. Let $X=\{a, b\}$. Define a function $G: X \times X \times X \mathbb{R}$ by

$$
G(a, a, a)=G(b, b, b)=0, \quad G(a, a, b)=1, \quad G(a, b, b)=2
$$

and extend $G$ to $X \times X \times X$ by using the symmetry in the variables. Then it is clear that $(X, G)$ is a $G$-metric space.

Definition 2.6. A $G$-metric space $(X, G)$ is said to be G-complete if every G-Cauchy sequence in $(X, G)$ is $G$-convergent in $(X, G)$.

For more details about the following definitions, we refer the reader to [6,7].

Definition 2.7. Let $X$ be a non-empty set and $F: X \times X \rightarrow X$ be a given mapping. An element $(x, y) \in X \times X$ is called a coupled fixed point of $F$ if $F(x, y)=x$ and $F(y, x)$ $=y$.

Definition 2.8. Let $(X, \leq)$ be a partially ordered set. A mapping $F: X \times X \rightarrow X$ is said to have the mixed monotone property if $F(x, y)$ is monotone non-decreasing in $x$ and is monotone non-increasing in $y$, that is, for any $x, y \in X$,

$$
x_{1}, x_{2} \in X, x_{1} \leq x_{2} \Rightarrow F\left(x_{1}, y\right) \leq F\left(x_{2}, y\right)
$$

and

$$
y_{1}, y_{2} \in X, y_{1} \leq y_{2} \Rightarrow F\left(x, y_{2}\right) \leq F\left(x, y_{1}\right) .
$$

Lakshmikantham and Ćirić [7] introduced the concept of a $g$-mixed monotone mapping.

Definition 2.9. Let $(X, \leq)$ be a partially ordered set, $F: X \times X \rightarrow X$ and $g: X \rightarrow X$ be mappings. The mapping $F$ is said to have the mixed g-monotone property if $F(x, y)$ is monotone $g$-non-decreasing in $x$ and is monotone $g$-non-increasing in $y$, that is, for any $x, y \in X$,

$$
x_{1}, x_{2} \in X, g x_{1} \leq g x_{2} \Rightarrow F\left(x_{1}, y\right) \leq F\left(x_{2}, y\right)
$$

and

$$
y_{1}, y_{2} \in X, g y_{1} \leq g y_{2} \Rightarrow F\left(x, y_{2}\right) \leq F\left(x, y_{1}\right) .
$$


Definition 2.10. Let $X$ be a non-empty set, $F: X \times X \rightarrow X$ and $g: X \rightarrow X$ be mappings. An element $(x, y) \in X \times X$ is called a coupled coincidence point of $F$ and $g$ if $F$ $(x, y)=g x$ and $F(y, x)=g y$.

Definition 2.11. Let $X$ be a non-empty set, $F: X \times X \rightarrow X$ and $g: X \rightarrow X$ be mappings. An element $(x, y) \in X \times X$ is called a coupled common fixed point of $F$ and $g$ if $F(x, y)=g x=x$ and $F(y, x)=g y=y$.

Definition 2.12. Let $X$ be a non-empty set, $F: X \times X \rightarrow X$ and $g: X \rightarrow X$ be mappings. We say that $F$ and $g$ are commutative if $g(F(x, y))=F(g x, g y)$ for all $x, y \in X$.

Definition 2.13. Let $X$ be a non-empty set, $F: X \times X \rightarrow X$ and $g: X \rightarrow X$ be mappings. Then $F$ and $g$ are said to be weak ${ }^{*}$ compatible (or $w^{*}$-compatible) if $g(F(x, x))=$ $F(g x, g x)$ whenever $g(x)=F(x, x)$.

\section{Main results}

The following is the first result.

Theorem 3.1. Let $(X, \leq)$ be a partially ordered set and $(X, G)$ be a complete G-metric space. Let $F: X \times X \rightarrow X$ and $g: X \rightarrow X$ be continuous mappings such that $F$ has the mixed g-monotone property and $g$ commutes with $F$. Assume that there are altering distance functions $\psi$ and $\varphi$ such that

$$
\begin{aligned}
& \psi(G(F(x, y), F(u, v), F(w, z))) \\
\leq & \psi(\max \{G(g x, g u, g w), G(g y, g v, g z)\})-\phi(\max \{G(g x, g u, g w), G(g y, g v, g z)\})
\end{aligned}
$$

for all $x, y, u, v, w, z \in X$ with $g w \leq g u \leq g x$ and $g y \leq g v \leq g z$. Also, suppose that $F(X$ $\times X) \subseteq g(X)$. If there exist $x_{0}, y_{0} \in X$ such that $g x_{0} \leq F\left(x_{0}, y_{0}\right)$ and $F\left(y_{0}, x_{0}\right) \leq g y_{0}$, then $F$ and $g$ have a coupled coincidence point.

Proof. Let $x_{0}, y_{0} \in X$ such that $g x_{0} \leq F\left(x_{0}, y_{0}\right)$ and $F\left(y_{0}, x_{0}\right) \leq g y_{0}$. Since we have $F(X$ $\times X) \subseteq g(X)$, we can choose $x_{1}, y_{1} \in X$ such that $g x_{1}=F\left(x_{0}, y_{0}\right)$ and $g y_{1}=F\left(y_{0}, x_{0}\right)$. Again, since $F(X \times X) \subseteq g(X)$, we can choose $x_{2}, y_{2} \in X$ such that $g x_{2}=F\left(x_{1}, y_{1}\right)$ and $g y_{2}=F\left(y_{1}, x_{1}\right)$. Since $F$ has the mixed $g$-monotone property, we have $g x_{0} \leq g x_{1} \leq g x_{2}$ and $g y_{2} \leq g y_{1} \leq g y_{0}$. Continuing this process, we can construct two sequences $\left(x_{n}\right)$ and $\left(y_{n}\right)$ in $X$ such that

$$
g x_{n}=G\left(x_{n-1}, y_{n-1}\right) \leq g x_{n+1}=F\left(x_{n}, y_{n}\right)
$$

and

$$
g y_{n+1}=F\left(y_{n}, x_{n}\right) \leq g y_{n}=F\left(y_{n-1}, x_{n-1}\right) .
$$

If, for some integer $n$, we have $\left(g x_{n+1}, g y_{n+1}\right)=\left(g x_{n}, g y_{n}\right)$, then $F\left(x_{n}, y_{n}\right)=g x_{n}$ and $F$ $\left(y_{n}, x_{n}\right)=g y_{n}$, that is, $\left(x_{n}, y_{n}\right)$ is a coincidence point of $F$ and $g$. So, from now on, we assume that $\left(g x_{n+1}, g y_{n+1}\right) \neq\left(g x_{n}, g y_{n}\right)$ for all $n \in \mathbb{N}$, that is, we assume that either $g x_{n}$ $+1 \neq g x_{n}$ or $g y_{n+1} \neq g y_{n}$.

We complete the proof with the following steps.

Step 1: We show that

$$
\lim _{n \rightarrow+\infty} \max \left\{G\left(g x_{n-1}, g x_{n}, g x_{n}\right\}, G\left(g y_{n-1}, g y_{n}, g y_{n}\right)\right\}=0 .
$$


For each $n \in \mathbb{N}$, using the inequality (1), we obtain

$$
\begin{aligned}
\psi\left(G\left(g x_{n+1}, g x_{n+1}, g x_{n}\right)\right)= & \psi\left(G\left(F\left(x_{n}, y_{n}\right), F\left(x_{n}, y_{n}\right), F\left(x_{n-1}, y_{n-1}\right)\right)\right) \\
\leq & \left.\psi\left(\max \left\{G\left(g x_{n}, g x_{n}, g x_{n-1}\right), G\left(g y_{n}, g y_{n}, g y_{n-1}\right)\right)\right\}\right) \\
& \left.-\phi\left(\max \left\{G\left(g x_{n}, g x_{n}, g x_{n-1}\right), G\left(g y_{n}, g y_{n}, g y_{n-1}\right)\right)\right\}\right) \\
\leq & \left.\psi\left(\max \left\{G\left(g x_{n}, g x_{n}, g x_{n-1}\right), G\left(g y_{n}, g y_{n}, g y_{n-1}\right)\right)\right\}\right) .
\end{aligned}
$$

Since $\psi$ is a non-decreasing function, we get

$$
\left.G\left(g x_{n+1}, g x_{n+1}, g x_{n}\right) \leq \max \left\{G\left(g x_{n}, g x_{n}, g x_{n-1}\right), G\left(g y_{n}, g y_{n}, g y_{n-1}\right)\right)\right\}
$$

On the other hand, we have

$$
\begin{aligned}
\psi\left(G\left(g y_{n}, g y_{n+1}, g y_{n+1}\right)\right)= & \psi\left(G\left(F\left(y_{n-1}, x_{n-1}\right), F\left(y_{n} . x_{n}\right), F\left(y_{n}, x_{n}\right)\right)\right) \\
\leq & \psi\left(\max \left\{G\left(g x_{n-1}, g x_{n}, g x_{n}\right), G\left(g y_{n-1}, g y_{n}, g y_{n}\right)\right\}\right) \\
& -\phi\left(\max \left\{G\left(g x_{n-1}, g x_{n}, g x_{n}\right), G\left(g y_{n-1}, g y_{n}, g y_{n}\right)\right\}\right) \\
\leq & \psi\left(\max \left\{G\left(g x_{n-1}, g x_{n}, g x_{n}\right), G\left(g y_{n-1}, g y_{n}, g y_{n}\right)\right\}\right) .
\end{aligned}
$$

Since $\psi$ is a non-decreasing function, we get

$$
G\left(g y_{n}, g y_{n+1}, g y_{n+1}\right) \leq \max \left\{G\left(g x_{n-1}, g x_{n}, g x_{n}\right), G\left(g y_{n-1}, g y_{n}, g y_{n}\right)\right\} .
$$

Thus, by (4) and (6), we have

$$
\begin{aligned}
& \max \left\{G\left(g x_{n}, g x_{n+1}, g x_{n+1}\right), G\left(g y_{n}, g y_{n+1}, g y_{n+1}\right)\right\} \\
& \leq \max \left\{G\left(g x_{n-1}, g x_{n}, g x_{n}\right), G\left(g y_{n-1}, g y_{n}, g y_{n}\right)\right\} .
\end{aligned}
$$

Thus $\left(\max \left\{G\left(g x_{n-1}, g x_{n}, g x_{n}\right), G\left(g y_{n-1}, g y_{n}, g y_{n}\right)\right\}\right)$ is a non-negative decreasing sequence. Hence, there exists $r \geq 0$ such that

$$
\lim _{n \rightarrow+\infty} \max \left\{G\left(g x_{n-1}, g x_{n}, g x_{n}\right), G\left(g y_{n-1}, g y_{n}, g y_{n}\right)\right\}=r
$$

Now, we show that $r=0$. Since $\varphi:[0,+\infty) \rightarrow[0,+\infty)$ is a non-decreasing function, then, for any $a, b \in[0,+\infty)$, we have $\psi(\max \{a, b\})=\max \{\psi(a), \psi(b)\}$. Thus, by (3)) and (5), we have

$$
\begin{aligned}
\psi\left(\max \left\{G\left(g x_{n-1}, g x_{n}, g x_{n}\right), G\left(g y_{n-1}, g y_{n}, g y_{n}\right)\right\}\right) \\
=\max \left\{\psi\left(G\left(g x_{n-1}, g x_{n}, g x_{n}\right)\right), \psi\left(G\left(g y_{n-1}, g y_{n}, g y_{n}\right)\right)\right\} \\
\leq \psi\left(\max \left\{G\left(g x_{n-1}, g x_{n}, g x_{n}\right), G\left(g y_{n-1}, g y_{n}, g y_{n}\right)\right\}\right) \\
\quad-\phi\left(\max \left\{G\left(g x_{n-1}, g x_{n}, g x_{n}\right), G\left(g y_{n-1}, g y_{n}, g y_{n}\right)\right\}\right) .
\end{aligned}
$$

Letting $n \rightarrow+\infty$ in the above inequality and using the continuity of $\psi$, we get

$$
\psi(r) \leq \psi(r)-\phi(r)
$$

Hence $\varphi(r)=0$. Thus $r=0$ and (2) holds.

Step 2: We show that $\left(g x_{n}\right)$ and $\left(g y_{n}\right)$ are G-Cauchy sequences. Assume that $\left(x_{n}\right)$ or $\left(y_{n}\right)$ is not a G-Cauchy sequence, that is,

$$
\lim _{n, m \rightarrow+\infty} G\left(g x_{m}, g x_{n}, g x_{n}\right) \neq 0
$$


or

$$
\lim _{n, m \rightarrow+\infty} G\left(g y_{m}, g y_{n}, g y_{n}\right) \neq 0 .
$$

This means that there exists $\epsilon>0$ for which we can find subsequences of integers ( $m$ $(k))$ and $(n(k))$ with $n(k)>m(k)>k$ such that

$$
\max \left\{G\left(\left(g x_{m(k)}\right), G\left(g x_{n(k)}\right), G\left(g x_{n(k)}\right)\right), G\left(\left(g y_{m(k)}\right), G\left(g y_{n(k)}\right), G\left(g y_{n(k)}\right)\right)\right\} \geq \varepsilon .
$$

Further, corresponding to $m(k)$ we can choose $n(k)$ in such a way that it is the smallest integer with $n(k)>m(k)$ and satisfying (7). Then we have

$$
\max \left\{G\left(\left(g x_{m(k)}\right), G\left(g x_{n(k)-1}\right), G\left(g x_{n(k)-1}\right)\right), G\left(\left(g y_{m(k)}\right), G\left(g y_{n(k)-1}\right), G\left(g y_{n(k)-1}\right)\right)\right\}<\varepsilon .
$$

Thus, by $\left(G_{5}\right)$ and $(8)$, we have

$$
\begin{aligned}
& G\left(g x_{m(k)}, g x_{n(k)}, g x_{n(k)}\right) \\
\leq & G\left(g x_{m(k)}, g x_{n(k)-1}, g x_{n(k)-1}\right)+G\left(g x_{n(k)-1}, g x_{n(k)}, g x_{n(k)}\right) \\
\leq & G\left(g x_{m(k)}, g x_{m(k)-1}, g x_{m(k)-1}\right)+G\left(g x_{m(k)-1}, g x_{n(k)-1}, g x_{n(k)-1}\right) \\
& +G\left(g x_{n(k)-1}, g x_{n(k)}, g x_{n(k)}\right) \\
\leq & 2 G\left(g x_{m(k)}, g x_{m(k)}, g x_{m(k)-1}\right)+G\left(g x_{m(k)-1}, g x_{n(k)-1}, g x_{n(k)-1}\right) \\
& +G\left(g x_{n(k)-1}, g x_{n(k)}, g x_{n(k)}\right) \\
< & 2 G\left(g x_{m(k)}, g x_{m(k)}, g x_{m(k)-1}\right)+\varepsilon+G\left(g x_{n(k)-1}, g x_{n(k)}, g x_{n(k)}\right) .
\end{aligned}
$$

Thus, by (2), we have

$$
\limsup _{k \rightarrow+\infty} G\left(g x_{m(k)}, g x_{n(k)}, g x_{n(k)}\right) \leq \limsup _{k \rightarrow+\infty} G\left(g x_{m(k)-1}, g x_{n(k)-1}, g x_{n(k)-1}\right) \leq \varepsilon .
$$

Similarly, we have

$$
\limsup _{k \rightarrow+\infty} G\left(g y_{m(k)}, g y_{n(k)}, g y_{n(k)}\right) \leq \limsup _{k \rightarrow+\infty} G\left(g y_{m(k)-1}, g y_{n(k)-1}, g y_{n(k)-1}\right) \leq \varepsilon .
$$

Thus, by (9) and (10), we have

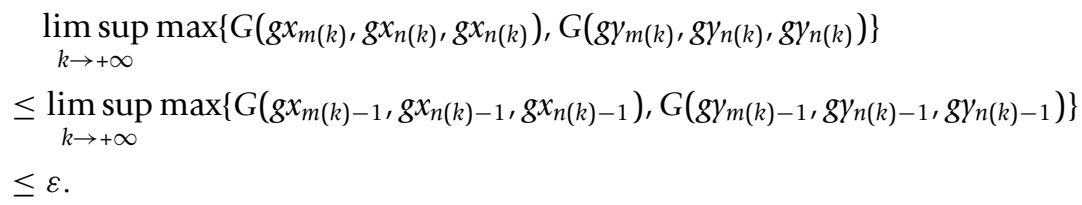

Using (7), we get

$$
\begin{aligned}
& \limsup _{k \rightarrow+\infty} \max \left\{G\left(g x_{m(k)}, g x_{n(k)}, g x_{n(k)}\right), G\left(g y_{m(k)}, g y_{n(k)}, g y_{n(k)}\right)\right\} \\
= & \limsup _{k \rightarrow+\infty} \max \left\{G\left(g x_{m(k)-1}, g x_{n(k)-1}, g x_{n(k)-1}\right), G\left(g y_{m(k)-1}, g y_{n(k)-1}, g y_{n(k)-1}\right)\right\} \\
= & \varepsilon .
\end{aligned}
$$

Now, using the inequality (1), we obtain

$$
\begin{aligned}
& \psi\left(G\left(g x_{n(k)}, g x_{n(k)}, G\left(g x_{m(k)}\right)\right)\right. \\
= & \psi\left(G\left(F\left(x_{n(k)-1}, y_{n(k)-1}\right), F\left(x_{n(k)-1}, y_{n(k)-1}\right), F\left(x_{m(k)-1}, y_{m(k)-1}\right)\right)\right) \\
\leq & \psi\left(\max \left\{G\left(g x_{n(k)-1}, g x_{n(k)-1}, g x_{m(k)-1}\right), G\left(g y_{n(k)-1}, y_{n(k)-1}, y_{m(k)-1}\right)\right)\right) \\
& -\phi\left(\max \left\{G\left(g x_{n(k)-1}, g x_{n(k)-1}, g x_{m(k)-1}\right), G\left(g y_{n(k)-1}, y_{n(k)-1}, y_{m(k)-1}\right)\right)\right)
\end{aligned}
$$


and

$$
\begin{aligned}
& \psi\left(G\left(g y_{m(k)}, g y_{n(k)}, g y_{n(k)}\right)\right) \\
= & \psi\left(G\left(F\left(y_{m(k)-1}, x_{m(k)-1}\right), F\left(y_{n(k)-1}, x_{n(k)-1}\right), F\left(y_{n(k)-1}, x_{n(k)-1}\right)\right)\right) \\
\leq & \psi\left(\max \left\{G\left\{g y_{m(k)-1}, g y_{n(k)-1}, g y_{n(k)-1}\right), G\left(g x_{m(k)}, g x_{n(k)-1}, g x_{n(k)-1}\right)\right\}\right) \\
& -\phi\left(\max \left\{G\left(g y_{m(k)-1}, g y_{n(k)-1}, g y_{n(k)-1}\right), G\left(g x_{m(k)-1}, g x_{n(k)-1}, g x_{n(k)-1}\right)\right\}\right) .
\end{aligned}
$$

Thus, by (12) and (13), we get

$$
\begin{aligned}
& \psi\left(\max \left\{G\left(g x_{m(k)}, g x_{n(k)}, g x_{n(k)}\right), G\left(g y_{m(k)}, g y_{n(k)}, g y_{n(k)}\right)\right\}\right) \\
= & \max \left\{\psi\left(G\left(g x_{m(k)}, g x_{n(k)}, g x_{n(k)}\right)\right), \psi\left(G\left(g y_{m(k)}, g y_{n(k)}, g y_{n(k)}\right)\right)\right\} \\
\leq & \psi\left(\max \left\{G\left(g y_{m(k)-1}, g y_{n(k)-1}, g y_{n(k)-1}\right), G\left(g x_{m(k)-1}, g x_{n(k)-1}, g x_{n(k)-1}\right)\right\}\right) \\
& -\phi\left(\max \left\{G\left(g y_{m(k)-1}, g y_{n(k)-1}, g y_{n(k)-1}\right), G\left(g x_{m(k)-1}, g x_{n(k)-1}, g x_{n(k)-1}\right)\right\}\right) .
\end{aligned}
$$

Letting $k \rightarrow+\infty$ in the above inequality and using (11) and the fact that $\psi$ and $\varphi$ are continuous, we get

$$
\psi(\varepsilon) \leq \psi(\varepsilon)-\phi(\varepsilon)
$$

Hence $\varphi(\epsilon)=0$ and so $\epsilon=0$, which is a contradiction. Therefore, $\left(g x_{n}\right)$ and $\left(g y_{n}\right)$ are G-Cauchy sequences.

Step 3: The existence of a coupled coincidence point. Since $\left(g x_{n}\right)$ and $\left(g y_{n}\right)$ are GCauchy sequences in a complete $G$-metric space $(X, G)$, there exist $x, y \in X$ such that $\left(g x_{n}\right)$ and $(g y n)$ are $G$-convergent to points $x$ and $y$, respectively, that is,

$$
\lim _{n \rightarrow+\infty} G\left(g x_{n}, g x_{n}, x\right)=\lim _{n \rightarrow+\infty} G\left(g x_{n}, x, x\right)=0
$$

and

$$
\lim _{n \rightarrow+\infty} G\left(g y_{n}, g y_{n}, y\right)=\lim _{n \rightarrow+\infty} G\left(g y_{n}, y, y\right)=0
$$

Then, by (14), (15) and the continuity of $g$, we have

$$
\lim _{n \rightarrow+\infty} G\left(g\left(g x_{n}\right), g\left(g x_{n}\right), g x\right)=\lim _{n \rightarrow+\infty} G\left(g\left(g x_{n}\right), g x, g x\right)=0
$$

and

$$
\lim _{n \rightarrow+\infty} G\left(g\left(g y_{n}\right), g\left(g y_{n}\right), g y\right)=\lim _{n \rightarrow+\infty} G\left(g\left(g y_{n}\right), g y, g y\right)=0
$$

Therefore, $\left(g\left(g x_{n}\right)\right)$ is G-convergent to $g x$ and $\left(g\left(g y_{n}\right)\right)$ is G-convergent to $g y$. Since $F$ and $g$ commute, we get

$$
g\left(g x_{n+1}\right)=g\left(F\left(x_{n}, y_{n}\right)\right)=F\left(g x_{n}, g y_{n}\right)
$$

and

$$
g\left(g y_{n+1}\right)=g\left(F\left(y_{n}, x_{n}\right)\right)=F\left(g y_{n}, g x_{n}\right) .
$$

Using the continuity of $F$ and letting $n \rightarrow+\infty$ in (18) and (19), we get $g x=F(x, y)$ and $g y=F(y, x)$. This implies that $(x, y)$ is a coupled coincidence point of $F$ and $g$. This completes the proof.

Tacking $g=I_{X}$ (: the identity mapping) in Theorem 3.1., we obtain the following coupled fixed point result. 
Corollary 3.1. Let $(X, \leq)$ be a partially ordered set and $(X, G)$ be a complete $G$ metric space. Let $F: X \times X \rightarrow X$ be a continuous mapping satisfying the mixed monotone property. Assume that there exist the altering distance functions $\psi$ and $\varphi$ such that

$$
\begin{aligned}
& \psi(G(F(x, y), F(u, v), F(w, z))) \\
\leq & \psi(\max \{G(x, u, w), G(y, v, z)\})-\phi(\max \{G(x, u, w), G(y, v, z)\})
\end{aligned}
$$

for all $x, y, u, v, w, z \in X$ with $w \leq u \leq x$ and $y \leq v \leq z$. If there exist $x_{0}, y_{0} \in X$ such that $x_{0} \leq F\left(x_{0}, y_{0}\right)$ and $F\left(y_{0}, x_{0}\right) \leq y_{0}$, then $F$ has a coupled fixed point.

Now, we derive coupled coincidence point results without the continuity hypothesis of the mappings $F, g$ and the commutativity hypothesis of $F, g$. However, we consider the additional assumption on the partially ordered set $(X, \leq)$.

We need the following definition.

Definition 3.1. Let $(X, \leq)$ be a partially ordered set and $G$ be a $G$-metric on $X$. We say that $(X, G, \leq)$ is regular if the following conditions hold:

(1) if a non-decreasing sequence $\left(x_{n}\right)$ is such that $x_{n} \rightarrow x$, then $x_{n} \leq x$ for all $n \in \mathbb{N}$,

(2) if a non-increasing sequence $\left(y_{n}\right)$ is such that $y_{n} \rightarrow y$, then $y \leq y_{n}$ for all $n \in \mathbb{N}$.

The following is the second result.

Theorem 3.2. Let $(X, \leq)$ be a partially ordered set and $G$ be a G-metric on $\times$ such that $(X, G, \leq)$ is regular. Assume that there exist the altering distance functions $\psi, \varphi$ and mappings $F: X \times X \rightarrow X$ and $g: X \rightarrow X$ such that

$$
\begin{aligned}
& \psi(G(F(x, y), F(u, v), F(w, z))) \\
\leq & \psi(\max \{G(g x, g u, g w), G(g y, g v, g z)\})-\phi(\max \{G(g x, g u, g w), G(g y, g v, g z)\})
\end{aligned}
$$

for all $x, y, u, v, w, z \in X$ with $g w \leq g u \leq g x$ and $g y \leq g v \leq g z$. Suppose also that $(g(X)$, $G)$ is G-complete, $F$ has the mixed $g$-monotone property and $F(X \times X) \subseteq g(X)$. If there exist $x_{0}, y_{0} \in X$ such that $g x_{0} \leq F\left(x_{0}, y_{0}\right)$ and $F\left(y_{0}, x_{0}\right) \leq g y_{0}$, then $F$ and $g$ have a coupled coincidence point.

Proof. Following Steps 1 and 2 in the proof of Theorem 3.1., we know that $\left(g x_{n}\right)$ and $\left(g y_{n}\right)$ are G-Cauchy sequences in $g(X)$ with $g x_{n} \leq g x_{n+1}$ and $g y_{n} \geq g y_{n+1}$ for all $n \in \mathbb{N}$. Since $(g(X), G)$ is $G$-complete, there exist $x, y \in X$ such that $g x_{n} \rightarrow g x$ and $g y_{n} \rightarrow g y$. Since $(X, G, \leq)$ is regular, we have $g x_{n} \leq g x$ and $g y \leq g y_{n}$ for all $n \in \mathbb{N}$. Thus we have

$$
\begin{aligned}
\psi\left(G\left(F(x, y), g x_{n+2}, g x_{n+1}\right)\right)= & \psi\left(G\left(F(x, y), F\left(x_{n+1}, y_{n+1}\right), F\left(g x_{n}, g y_{n}\right)\right)\right) \\
\leq & \psi\left(\max \left\{G\left(g x, g x_{n+1}, g x_{n}\right), G\left(g y, g y_{n+1}, g x_{n}\right)\right\}\right) \\
& -\phi\left(\max \left\{G\left(g x, g x_{n+1}, g x_{n}\right), G\left(g y, g y_{n+1}, g y_{n}\right)\right\}\right) .
\end{aligned}
$$

Letting $n \rightarrow+\infty$ in the above inequality and using the continuity of $\psi$ and $\varphi$, we obtain $\psi(G(F(x, y), g x, g x))=0$, which implies that $G(F(x, y), g x, g x)=0$. Therefore, $F(x$, $y)=g x$.

Similarly, one can show that $F(y, x)=g y$. Thus $(x, y)$ is a coupled coincidence point of $F$ and $g$, this completes the proof.

Tacking $g=I_{X}$ in Theorem 3.2., we obtain the following result.

Corollary 3.2. Let $(X, \leq)$ be a partially ordered set and $G$ be a G-metric on $X$ such that $(X, G, \leq)$ is regular and $(X, G)$ is $G$-complete. Assume that there exist the altering distance functions $\psi, \varphi$ and a mapping 
$F: X \times X \rightarrow X$ having the mixed monotone property such that

$\psi(G(F(x, y), F(u, v), F(w, z)))$

$$
\leq \psi(\max \{G(x, u, w), G(y, v, z)\})-\phi(\max \{G(x, u, w), G(y, v, z)\})
$$

for all $x, y, u, v, w, z \in X$ with $w \leq u \leq x$ and $y \leq v \leq z$. If there exist $x_{0}, y_{0} \in X$ such that $x_{0} \leq F\left(x_{0}, y_{0}\right)$ and $F\left(y_{0}, x_{0}\right) \leq y_{0}$, then $F$ has a coupled fixed point.

Now, we prove the existence and uniqueness theorem of a coupled common fixed point. If $(X, \leq)$ is a partially ordered set, we endow the product set $X \times X$ with the partial order defined by

$$
(x, y) \leq(u, v) \Leftrightarrow x \leq u, v \leq \gamma .
$$

Theorem 3.3. In addition to the hypotheses of Theorem 3.1., suppose that, for any (x, $y),\left(x^{*}, y^{*}\right) \in X \times X$, there exists $(u, v) \in X \times X$ such that $(F(u, v), F(v, u))$ is comparable with $(F(x, y), F(y, x))$ and $\left(F\left(x^{*}, y^{*}\right), F\left(y^{*}, x^{*}\right)\right)$. Then $F$ and $g$ have a unique coupled common fixed point, that is, there exists a unique $(x, y) \in X \times X$ such that $x=g x=F$ $(x, y)$ and $y=g y=F(y, x)$.

Proof. From Theorem 3.1., the set of coupled coincidence points is non-empty. We shall show that if $(x, y)$ and $\left(x^{*}, y^{*}\right)$ are coupled coincidence points, then

$$
g x=g x^{*}, \quad g y=g y^{*} .
$$

By the assumption, there exists $(u, v) \in X \times X$ such that $(F(u, v), F(v, u))$ is comparable to $(F(x, y), F(y, x))$ and $\left(F\left(x^{*}, y^{*}\right), F\left(y^{*}, x^{*}\right)\right)$. Without the restriction to the generality, we can assume that $(F(x, y), F(y, x)) \leq(F(u, v), F(v, u))$ and $\left(F\left(x^{*}, y^{*}\right), F\left(y^{*}, x^{*}\right)\right) \leq(F$ $(u, v), F(v, u))$. Put $u_{0}=u, v_{0}=v$ and choose $u_{1}, v_{1} \in X$ so that $g u_{1}=F\left(u_{0}, v_{0}\right)$ and $g v_{1}$ $=F\left(v_{0}, u_{0}\right)$. As in the proof of Theorem 3.1., we can inductively define the sequences $\left(u_{n}\right)$ and $\left(v_{n}\right)$ such that

$$
g u_{n+1}=F\left(u_{n}, v_{n}\right), \quad g v_{n+1}=F\left(v_{n}, u_{n}\right) .
$$

Further, set $x_{0}=x, y_{0}=y, x_{0}^{*}=x^{*}, y_{0}^{*}=y^{*}$ and, by the same way, define the sequences $\left(x_{n}\right),\left(y_{n}\right)$ and $\left(x_{n}^{*}\right),\left(y_{n}^{*}\right)$. Since $(g x, g y)=(F(x, y), F(y, x))=\left(g x_{1}, g y_{1}\right)$ and $(F$ $(u, v), F(v, u))=\left(g u_{1}, g v_{1}\right)$ are comparable, $g x \leq g u_{1}$ and $g v_{1} \leq g y$. One can show, by induction, that

$$
g x \leq g u_{n}, \quad g v_{n} \leq g y
$$

for all $n \in \mathbb{N}$. From (1), we have

$$
\begin{aligned}
\psi\left(G\left(g x, g x, g u_{n+1}\right)\right)= & \psi\left(G\left(F(x, y), F(x, y), F\left(u_{n}, v_{n}\right)\right)\right) \\
\leq & \psi\left(\max \left\{G\left(g x, g x, g u_{n}\right), G\left(g y, g y, g v_{n}\right)\right\}\right) \\
& -\phi\left(\max \left\{G\left(g x, g x, g u_{n}\right), G\left(g y, g y, g v_{n}\right)\right\}\right)
\end{aligned}
$$

and

$$
\begin{aligned}
\psi\left(G\left(g y, g y, g v_{n+1}\right)\right)= & \psi\left(G\left(F(y, x), F(y, x), F\left(v_{n}, u_{n}\right)\right)\right) \\
\leq & \psi\left(\max \left\{G\left(g x, g x, g u_{n}\right), G\left(g y, g y, g v_{n}\right)\right\}\right) \\
& -\phi\left(\max \left\{G\left(g x, g x, g u_{n}\right), G\left(g y, g y, g v_{n}\right)\right\}\right) .
\end{aligned}
$$


Hence it follows that

$$
\begin{aligned}
& \psi\left(\max \left\{G\left(g x, g x, g u_{n+1}\right), G\left(g y, g y, g v_{n+1}\right)\right\}\right) \\
= & \max \left\{\psi\left(G\left(g x, g x, g u_{n+1}\right)\right), \psi\left(G\left(g y, g y, g v_{n+1}\right)\right)\right\} \\
\leq & \psi\left(\max \left\{G\left(g x, g x, g u_{n}\right), G\left(g y, g y, g v_{n}\right)\right\}\right) \\
& -\phi\left(\max \left\{G\left(g x, g x, g u_{n}\right), G\left(g y, g y, g v_{n}\right)\right\}\right) \\
\leq & \psi\left(\max \left\{G\left(g x, g x, g u_{n}\right), G\left(g y, g y, g v_{n}\right)\right\}\right) .
\end{aligned}
$$

Since $\psi$ is non-decreasing, it follows that $\left(\max \left\{G\left(g x, g x, g u_{n}\right), G\left(g y, g y, g v_{n}\right)\right\}\right)$ is a decreasing sequence.

Hence there exists a non-negative real number $r$ such that

$$
\lim _{n \rightarrow+\infty} \max \left\{G\left(g x, g x, g u_{n}\right), G\left(g y, g y, g v_{n}\right)\right\}=r .
$$

Using (21) and letting $n \rightarrow+\infty$ in the above inequality, we get

$$
\psi(r) \leq \psi(r)-\phi(r)
$$

Therefore, $\varphi(r)=0$ and hence $r=0$. Thus

$$
\left.\lim _{n \rightarrow+\infty} G\left(g x, g x, g u_{n}\right)=\lim _{n \rightarrow+\infty} G\left(g y, g y, g v_{n}\right)\right\}=0 .
$$

Similarly, we can show that

$$
\lim _{n \rightarrow+\infty} G\left(g x^{*}, g x^{*}, g u_{n+1}\right)=\lim _{n \rightarrow+\infty} G\left(g y^{*}, g y^{*}, g v_{n+1}\right)=0 .
$$

Thus, by $\left(G_{5}\right),(22)$, and (23), we have, as $n \rightarrow+\infty$,

$$
G\left(g x, g x, g x^{*}\right) \leq G\left(g x, g x, g u_{n+1}\right)+p\left(g u_{n+1}, g u_{n+1}, g x^{*}\right) \rightarrow 0
$$

and

$$
G\left(g y, g y, g y^{*}\right) \leq G\left(g y, g y, g v_{n+1}\right)+G\left(g v_{n+1}, g v_{n+1}, g y^{*}\right) \rightarrow 0
$$

Hence $g x=g x^{*}$ and $g y=g y^{*}$. Thus we proved (20).

On the other hand, since $g x=F(x, y)$ and $g y=F(y, x)$, by commutativity of $F$ and $g$, we have

$$
g(g x)=g(F(x, y))=F(g x, g y), \quad g(g y)=g(F(y, x))=F(g y, g x) .
$$

Denote $g x=z$ and $g y=w$. Then, from (24), it follows that

$$
g z=F(z, w), \quad g w=F(w, z)
$$

Thus $(z, w)$ is a coupled coincidence point. Then, from (20) with $x^{*}=z$ and $y^{*}=w$, it follows that $g z=g x$ and $g w=g y$, that is,

$$
g z=z, \quad g w=w .
$$

Thus, from (25) and (26), we have $z=g z=F(z, w)$ and $w=g w=F(w, z)$. Therefore, $(z, w)$ is a coupled common fixed point of $F$ and $g$.

To prove the uniqueness of the point $(z, w)$, assume that $(s, t)$ is another coupled common fixed point of $F$ and $g$. Then we have

$$
s=g s=F(s, t), \quad t=g t=F(t, s) .
$$


Since the pair $(s, t)$ is a coupled coincidence point of $F$ and $g$, we have $g s=g x=z$ and $g t=g y=w$. Thus $s=g s=g z=z$ and $t=g t=g w=w$. Hence, the coupled fixed point is unique. this completes the proof.

Now, we present coupled coincidence and coupled common fixed point results for mappings satisfying contractions of integral type. Denote by $\Lambda$ the set of functions $\alpha$ : $[0,+\infty) \rightarrow[0,+\infty)$ satisfying the following hypotheses:

(h1) $\alpha$ is a Lebesgue integrable mapping on each compact subset of $[0,+\infty)$,

(h2) for any $\varepsilon>0$, we have $\int_{0}^{\varepsilon} \alpha(s) \mathrm{d} s>0$.

Finally, we give the following results.

Theorem 3.4. Let $(X, \leq)$ be a partially ordered set and $(X, G)$ be a complete G-metric space. Let $F: X \times X \rightarrow X$ and $g: X \rightarrow X$ be continuous mappings such that $F$ has the mixed g-monotone property and $g$ commutes with $F$. Assume that there exist $\alpha, \beta \in \Lambda$ such that

$$
\leq \quad \int_{0}^{\max \{G(g x, g u, g w), G(g y, g v, g z)\}} \alpha(s) \mathrm{d} s
$$

for all $x, y, u, v, w, z \in X$ with $g w \leq g u \leq g x$ and $g y \leq g v \leq g z$. Also, suppose that $F(X$ $\times X) \subseteq g(X)$. If there exist $x_{0}, y_{0} \in X$ such that $g x_{0} \leq F\left(x_{0}, y_{0}\right)$ and $F\left(y_{0}, x_{0}\right) \leq g y_{0}$, then $F$ and $g$ have a coupled coincidence point.

Proof. We consider the functions $\psi, \varphi:[0,+\infty) \rightarrow[0,+\infty)$ defined by

$$
\psi(t)=\int_{0}^{t} \alpha(s) \mathrm{d} s, \quad \phi(t)=\int_{0}^{t} \beta(s) \mathrm{d} s
$$

for all $t \geq 0$. It is clear that $\psi$ and $\varphi$ are altering distance functions. Then the results follow immediately from Theorem 3.1.. This completes the proof.

Corollary 3.3. Let $(X, \leq)$ be a partially ordered set and $(X, G)$ be a complete $G$ metric space. Let $F: X \times X \rightarrow X$ be a continuous mappings satisfying the mixed monotone property. Assume that there exist $\alpha, \beta \in \Lambda$ such that

$$
\leq \int_{0}^{\max \{G(x, u, w), G(y, v, z)\}} \alpha(s) \mathrm{d} s-\int_{0}^{\max \{G(x, u, w), G(y, v, z)\}} \beta(s) \mathrm{d} s
$$

for all $x, y, u, v, w, z \in X$ with $w \leq u \leq x$ and $y \leq v \leq z$. If there exist $x_{0}, y_{0} \in X$ such that $x_{0} \leq F\left(x_{0}, y_{0}\right)$ and $F\left(y_{0}, x_{0}\right) \leq y_{0}$, then $F$ has a coupled fixed point.

Proof. Tacking $g=I_{X}$ in Theorem 3.3., we obtain Corollary 3.3.. 
Putting $\beta(s)=(1-k) \alpha(s)$ with $k \in[0,1)$ in Theorem 3.3., we obtain the following result.

Corollary 3.4. Let $(X, \leq)$ be a partially ordered set and $(X, G)$ be a complete $G$ metric space. Let $F: X \times X \rightarrow X$ and $g: X \rightarrow X$ be continuous mappings such that $F$ has the mixed g-monotone property and $g$ commutes with $F$. Assume that there exist $\alpha$ $\in \Lambda$ and $k \in[0,1)$ such that

$$
\int_{0}^{G(F(x, y), F(u, v), F(w, z))} \alpha(s) \mathrm{d} s \leq k \quad \int_{0}^{\max \{G(g x, g u, g w), G(g y, g v, g z)\}} \alpha(s) \mathrm{d} s
$$

for all $x, y, u, v, w, z \in X$ with $g w \leq g u \leq g x$ and $g y \leq g v \leq g z$. Also, suppose that $F(X$ $\times X) \subseteq g(X)$.

If there exist $x_{0}, y_{0} \in X$ such that $g x_{0} \leq F\left(x_{0}, y_{0}\right)$ and $F\left(y_{0}, x_{0}\right) \leq g y_{0}$, then $F$ and $g$ have a coupled coincidence point.

Tacking $\alpha(s)=1$ in Corollary 3.4., we obtain the following result.

Corollary 3.5. Let $(X, \leq)$ be a partially ordered set and $(X, G)$ be a complete $G$ metric space. Let $F: X \times X \rightarrow X$ and $g: X \rightarrow X$ be continuous mappings such that $F$ has the mixed $g$-monotone property and $g$ commutes with $F$. Assume that there exists $k$ $\in[0,1)$ such that

$$
G(F(x, y), F(u, v), F(w, z)) \leq k \max \{G(g x, g u, g w), G(g y, g v, g z)\}
$$

for all $x, y, u, v, w, z \in X$ with $g w \leq g u \leq g x$ and $g y \leq g v \leq g z$. Also, suppose that $F(X$ $\times X) \subseteq g(X)$. If there exist $x_{0}, y_{0} \in X$ such that $g x_{0} \leq F\left(x_{0}, y_{0}\right)$ and $F\left(y_{0}, x_{0}\right) \leq g y_{0}$, then $F$ and $g$ have a coupled coincidence point.

Corollary 3.6. Let $(X, \leq)$ be a partially ordered set and $(X, G)$ be a complete $G$ metric space. Let $F: X \times X \rightarrow X$ and $g: X \rightarrow X$ be continuous mappings such that $F$ has the mixed $g$-monotone property and $g$ commutes with $F$. Assume that there exist non-negative real numbers $a, b$ with $a+b \in[0,1)$ such that

$$
G(F(x, y), F(u, v), F(w, z)) \leq a G(g x, g u, g w)+b G(g y, g v, g z)
$$

for all $x, y, u, v, w, z \in X$ with $g w \leq g u \leq g x$ and $g y \leq g v \leq g z$. Also, suppose that $F(X$ $\times X) \subseteq g(X)$. If there exist $x_{0}, y_{0} \in X$ such that $g x_{0} \leq F\left(x_{0}, y_{0}\right)$ and $F\left(y_{0}, x_{0}\right) \leq g y_{0}$, then $F$ and $g$ have a coupled coincidence point.

Proof. We have

$$
a G(g x, g u, g w)+b G(g y, g v, g z) \leq(a+b) \max \{G(g x, g u, g w), G(g y, g v, g z)\}
$$

for all $x, y, u, v, w, z \in X$ with $g w \leq g u \leq g x$ and $g y \leq g v \leq g z$. Then Corollary 3.6. follows from Corollary 3.5.

Remark 3.1. Note that similar results can be deduced from Theorems 3.2. and 3.3..

Remark 3.2. (1) Theorem 3.1 in [36] is a special case of Theorem 3.1.

(2) Theorem 3.2 in [36] is a special case of Theorem 3.2.. 
Example 3.1. Let $X=0,1,2,3, \ldots$ and $G: X \times X \times X \rightarrow R^{+}$be defined as follows:

$$
G(x, y, z)=\left\{\begin{array}{cc}
x+y+z, & \text { if } x, y, z \text { are all distinct and different from zero } \\
x+z, & \text { if } x=y \neq z \text { and all are different from zero } \\
y+z+1, & \text { if } x=0, y \neq z \text { and } y, z \text { are different from zero } \\
y+2, & \text { if } x=0, z=y \neq 0 \\
1+z, & \text { if } x=0, y=0, z \neq 0 \\
0, & \text { if } x=y=z .
\end{array}\right.
$$

Then $(X, G)$ is a complete $G$-metric space [36]. Let a partial order $\preccurlyeq$ on $X$ be defined as follows: For $x, y \in X, x \leqslant y$ holds if $x>y$ and 3 divides $(x-y)$ and $3 \leqslant 1$ and $0 \leqslant 1$ hold. Let $F: X \times X \rightarrow X$ be defined as follows:

$$
F(x, y)=\left\{\begin{array}{l}
1, \quad \text { if } x \prec y, \\
0, \text { if otherwise }
\end{array}\right.
$$

Let $w \leqslant u \leqslant x \leqslant y \leqslant v \leqslant z$ hold, then equivalently, we have $w \geq u \geq x \geq y \geq v \geq z$. Then $F(x, y)=F(u, v)=F(w, z)=1$. Let $\psi(t)=t, \phi(t)=\left(1-\frac{k}{2}\right) t$ for $t \geq 0$ and $k \in$ $[0,1)$ and let $g(x)=x$ for $x \in X$. Thus left-hand side of $(1)$ is $G(1,1,1)=0$ and hence (1) is satisfied. Then with $x_{0}=81$ and $y_{0}=0$ the Theorem 3.2. is applicable to this example. It may be observed that in this example the coupled fixed point is not unique. Hence, $(0,0)$ and $(1,0)$ are two coupled fixed point of $F$.

\section{Acknowledgements}

YJC was supported by the Basic Science Research Program through the National Research Foundation of Korea (NRF) funded by the Ministry of Education, Science and Technology (Grant Number: 2011-0021821).

\section{Author details}

${ }^{1}$ Department of Mathematics Education and RINS, Gyeongsang National University, Chinju 660-701, Korea ${ }^{2}$ Department of Mathematics, Indiana University, Bloomington, IN 47405-7106, USA ${ }^{3}$ Department of Mathematics, Science and Research Branch, Islamic Azad University, Tehran, Iran ${ }^{4}$ Université de Tunis, Ecole Supérieur des Sciences et Techniques de Tunis, 5, Avenue Taha Hussein-Tunis, B.P.:56, Bab Menara-1008, Tunisie ${ }^{5}$ Department of Mathematics, Hashemite University, P.O. Box 150459, Zarqa 13115, Jordan

\section{Authors' contributions}

All authors carried out the proof. All authors conceived of the study, and participated in its design and coordination. All authors read and approved the final manuscript.

\section{Competing interests}

The authors declare that they have no competing interests.

Received: 22 August 2011 Accepted: 26 January 2012 Published: 26 January 2012

References

1. Ran, ACM, Reurings, MCB: A fixed point theorem in partially ordered sets and some applications to matrix equations. Proc Am Math Soc. 132, 1435-1443 (2004). doi:10.1090/S0002-9939-03-07220-4

2. Nieto, JJ, López, RR: Contractive mapping theorems in partially ordered sets and applications to ordinary differential equations. Order. 22, 223-239 (2005). doi:10.1007/s11083-005-9018-5

3. Nieto, JJ, López, RR: Existence and uniqueness of fixed point in partially ordered sets and applications to ordinary differential equations. Acta Math Sinica Engl Ser. 23(12):2205-2212 (2007). doi:10.1007/s10114-005-0769-0

4. Agarwal, RP, El-Gebeily, MA: O'Regan D: Generalized contractions in partially ordered metric spaces. Appl Anal. 87, 1-8 (2008). doi:10.1080/00036810701714164

5. O'Regan, D, Petrutel, A: Fixed point theorems for generalized contractions in ordered metric spaces. J Math Anal Appl. 341, 241-1252 (2008)

6. Bhaskar, TG, Lakshmikantham, V: Fixed point theorems in partially ordered metric spaces and applications. Nonlinear Anal. 65, 1379-1393 (2006). doi:10.1016/j.na.2005.10.017

7. Lakshmikantham, V, Cirić, LJ: Coupled fixed point theorems for nonlinear contractions in partially ordered metric spaces. Nonlinear Anal. 70, 4341-4349 (2009). doi:10.1016/j.na.2008.09.020

8. Abbas, M, Cho, YJ, Nazir, T: Common fixed point theorems for four mappings in TVS-valued cone metric spaces. J Math Inequal. 5, 287-299 (2011) 
9. Abbas, M, Khan, MA, Radenović, S: Common coupled fixed point theorem in cone metric space for $w$-compatible mappings. Appl Math Comput. 217, 195-202 (2010). doi:10.1016/j.amc.2010.05.042

10. Cho, YJ, He, G, Huang, NJ: The existence results of coupled quasi-solutions for a class of operator equations. Bull Korean Math Soc. 47, 455-465 (2010)

11. Cho, YJ, Saadati, R, Wang, S: Common fixed point theorems on generalized distance in order cone metric spaces. Comput Math Appl. 61, 1254-1260 (2011). doi:10.1016/j.camwa.2011.01.004

12. Cho, YJ, Shah, MH, Hussain, N: Coupled fixed points of weakly F-contractive mappings in topological spaces. Appl Math Lett. 24, 1185-1190 (2011). doi:10.1016/j.aml.2011.02.004

13. Ciric, L, Cakic, N, Rajovic, M, Ume, JS: Monotone generalized nonlinear contractions in partially ordered metric spaces. Fixed Point Theory Appl 2008(11) (2008). (ID 131294)

14. Gordji, ME, Cho, YJ, Baghani, H: Coupled fixed point theorems for contractions in intuitionistic fuzzy normed spaces. Math Comput Model. 54, 1897-1906 (2011). doi:10.1016/j.mcm.2011.04.014

15. Graily, E, Vaezpour, SM, Saadati, R, Cho, YJ: Generalization of fixed point theorems in ordered metric spaces concerning generalized distance. Fixed Point Theory Appl. 2011, 30 (2011). doi:10.1186/1687-1812-2011-30

16. Karapinar, E: Couple fixed point theorems for nonlinear contractions in cone metric spaces. Comput Math Appl. (2010)

17. Sabetghadam, F, Masiha, HP, Sanatpour, AH: Some coupled fixed point theorems in cone metric spaces. Fixed point Theory Appl 2009, 8 (2009). (ID 125426)

18. Samet, B: Coupled fixed point theorems for a generalized Meir-Keeler contraction in partially ordered metric spaces. Nonlinear Anal. 72, 4508-4517 (2010). doi:10.1016/j.na.2010.02.026

19. Samet, B, Vetro, C: Coupled fixed point, F-invariant set and fixed point of N-order. Ann Funct Anal. 1(2):46-56 (2010)

20. Samet, B, Yazidi, H: Coupled fixed point theorems in partially ordered $\varepsilon$-chainable metric spaces. J Math Comput Sci. 1, 142-151 (2010)

21. Sintunavarat, W, Cho, YJ, Kumam, P: Common fixed point theorems for c-distance in ordered cone metric spaces. Comput Math Appl. 62, 1969-1978 (2011). doi:10.1016/j.camwa.2011.06.040

22. Sintunavarat, W, Cho, YJ, Kumam, P: Coupled coincidence point theorems for contractions without commutative condition in intuitionistic fuzzy normed spaces. Fixed Point Theory Appl. 2011, 81 (2011). doi:10.1186/1687-1812-201181

23. Zhu, XH, Xiao, JZ: Note on "Coupled fixed point theorems for contractions in fuzzy metric spaces". Nonlinear Anal. 72 5475-5479 (2011)

24. Shatanawi, W: Partially ordered cone metric spaces and coupled fixed point results. Comput Math Appl. 60, 2508-2515 (2010). doi:10.1016/j.camwa.2010.08.074

25. Mustafa, Z, Sims, B: A new approach to generalized metric spaces. J Nonlinear Convex Anal. 7, 289-297 (2006)

26. Abbas, M, Rhoades, BE: Common fixed point results for non-commuting mappings without continuity in generalized metric spaces. Appl Math Comput. 215, 262-269 (2009). doi:10.1016/j.amc.2009.04.085

27. Chugh, R, Kadian, T, Rani, A, Rhoades, BE: Property $p$ in G-metric spaces. Fixed Point Theory Appl 2010, 12 (2010). (ID 401684)

28. Mustafa, Z, Sims, B: Some remarks concerning D-metric spaces. Proc Int Conference on Fixed Point Theory and Applications. pp. 189-198.Valencia, Spain (2003)

29. Mustafa, Z, Obiedat, H, Awawdehand, F: Some fixed point theorem for mapping on complete G-metric spaces. Fixed Point Theory Appl 2008, 12 (2008). (ID 189870)

30. Mustafa, Z, Sims, B: Fixed point theorems for contractive mapping in complete G- metric spaces. Fixed Point Theory Appl 2009, 10 (2009). (ID 917175)

31. Mustafa, Z, Shatanawi, W, Bataineh, M: Existence of fixed point results in G-metric spaces. Int J Math Anal 2009, 10 (2009). (ID 283028)

32. Shatanawi, W: Fixed point theory for contractive mappings satisfying $\Phi$-maps in G-metric spaces. Fixed Point Theory Appl 2010, 9 (2010). (ID 181650)

33. Abbas, M, Khan, AR, Nazir, T: Coupled common fixed point results in two generalized metric spaces. Appl Math Comput. (2011)

34. Shatanawi, W: Coupled fixed point theorems in generalized metric spaces. Hacet J Math Stat. 40(3):441-447 (2011)

35. Saadati, R, Vaezpour, SM, Vetro, P, Rhoades, BE: Fixed point theorems in generalized partially ordered G-metric spaces. Math Comput Model. 52, 797-801 (2010). doi:10.1016/j.mcm.2010.05.009

36. Choudhury, BS, Maity, P: coupled fixed point results in generalized metric spaces. Math Comput Model. 54, 73-79 (2011). doi:10.1016/j.mcm.2011.01.036

37. Khan, MS, Swaleh, M, Sessa, S: Fixed point theorems by altering distancces between the points. Bull Aust Math Soc. 30 1-9 (1984). doi:10.1017/S0004972700001659

doi:10.1186/1687-1812-2012-8

Cite this article as: Cho et al:: Nonlinear coupled fixed point theorems in ordered generalized metric spaces with integral type. Fixed Point Theory and Applications 2012 2012:8. 